\title{
EVOLUÇÃO DIAGENÉTICA DOS TURBIDITOS DA FORMAC̣ÃO BOM GOSTO NA ÁREA LESTE DA BACIA DE BARREIRINHAS, MA
}

\author{
JOSÉ AUGUSTO MARTINS CORRÊA* e WERNER TRUCKENBRODT*
}

\begin{abstract}
DIAGENETIC EVOLUTION OF THE TURBIDITE SANDSTONES OF THE BOM GOSTO FORMATION, EASTERN BARREIRINHAS BASIN, MARANHAO. The Albian Bom Gosto Formation was deposited in a marine environment during the initial phase of the Barreirinhas Basin formation, in the equatorial Brazilian margin. Arkoses are the main type of sandstones, varying from fine to coarse grained and showing a moderate sorting. These sediments have been subjected to a complex sequence of diagenetic events controlled by basin tectonics and provenance. The main phenomena are the results of chemical reactions in the mesodiagenetic stage. The chronologic sequence of diagenetic processes consists of: 1 . mechanical compaction; 2 . quartz and feldspar overgrowth; 3 . non-ferroan calcite and Fe-calcite cementation and replacement followed by partial dolomitization; 4 . development of secondary porosity essentially by the dissolution of calcite replacement and cement; and 5 . porosity reduction by mechanical compaction and precipitation of clay minerals (mainly kaolinite), quartz, feldspar, pyrite and anatase into the pore system. The secondary porosity was classified in four main categories: $A$. obvious dissolution porosity, subdivided into six classes based on corrosive and/or geometric grain features; $B$. regular intergranular porosity: $C$. microporosity, divided into two classes based on the textural position of kaolinite within the framework; and $D$, fracture porosity. Correlation between porosity classes and depth shows the importance of the ascendant leaching fluids which are responsible for most part of the secondary porosity generation, as well as for the transport of aluminium and silicium, which precipitated as kaolinite under favourable conditions. Silica probably was derived by pressure solution of quartz grains and feldspar replacement by calcite and kaolinite. Carbonate cement probably has its origin related to diagenetic phenomena within the adjacent shales (Arpoador and Tutóia formations). Authigenic clay minerals apparently have been formed through reactions which involved the dehydration of shales. They are the main agents of the low permo-porosity observed in Bom Gosto sandstones, once they reduce the secondary porosity and modify the pore system through particle migration and create large amounts of microporosity.
\end{abstract}

INTRODUÇÃo O estudo detalhado da diagênese de reservatórios siliciclásticos vem, nos últimos anos, recebendo uma maior atenção por parte das companhias petrolíferas. Os fenômenos diagenéticos que ocorrem no interior dos arenitos são predominantemente de caráter químico e desempenham um papel de suma importância na qualidade dos reservatórios ao longo do tempo.

A Bacia de Barreirinhas, cujos principais reservatórios estão associados a um sistema deltaico distal/prodelta e a turbiditos dentro do grupo Canárias (Lima et al. 1985), vem apresentando desde a sua descoberta até o presente momento bons indícios de óleo e gás. Entretanto, problemas de permeabilidade relacionados a fenômenos diagenéticos impedem a exploração comercial destes reservatórios. $\mathrm{O}$ principal objetivo deste trabalho foi, portanto, investigar a natureza e a forma de ocorrência dos minerais autigênicos, discutindo suas prováveis origens e ligações com a porosidade da rocha-reservatório. Foi escolhida para este estudo a área leste da bacia, onde os turbiditos, denominados por Pamplona (1969) de Formação Bom Gosto, apresentam bons indícios de hidrocarbonetos.

LOCALIZAÇÃO E ARCABOUÇO GEOLÓGICO A Bacia de Barreirinhas está localizada na costa do Estado do Maranhão, entre as cidades de São Luís e Parnaíba, e se encontra em parte submersa pelo Oceano Atlântico (Fig. 1). Com sua origem intimamente ligada à formação do Atlântico Equatorial, teve sua sedimentação iniciada no Eocretáceo. Os mais de $6.000 \mathrm{~m}$ de sedimentos foram divididos genericamente em dois grandes grupos: um terrígeno inferior, denominado Grupo Canárias, e outro, carbonático-pelítico, denominado Grupo Caju (Noguti 1967). Em 1969, Pamplona acrescentou o Grupo Humberto de Campos, posicionando-o acima do Grupo Caju. Baseados em dados sísmicos mais modernos e linhas de tempo mais confiáveis, Figueiredo et al. (1982) propuseram modificações significativas na coluna estratigráfica, principalmente no que diz respeito às formações e membros propostos por Pamplona (op. cit.). A nova coluna estratigráfica é composta de 11 formações distribuídas pelos

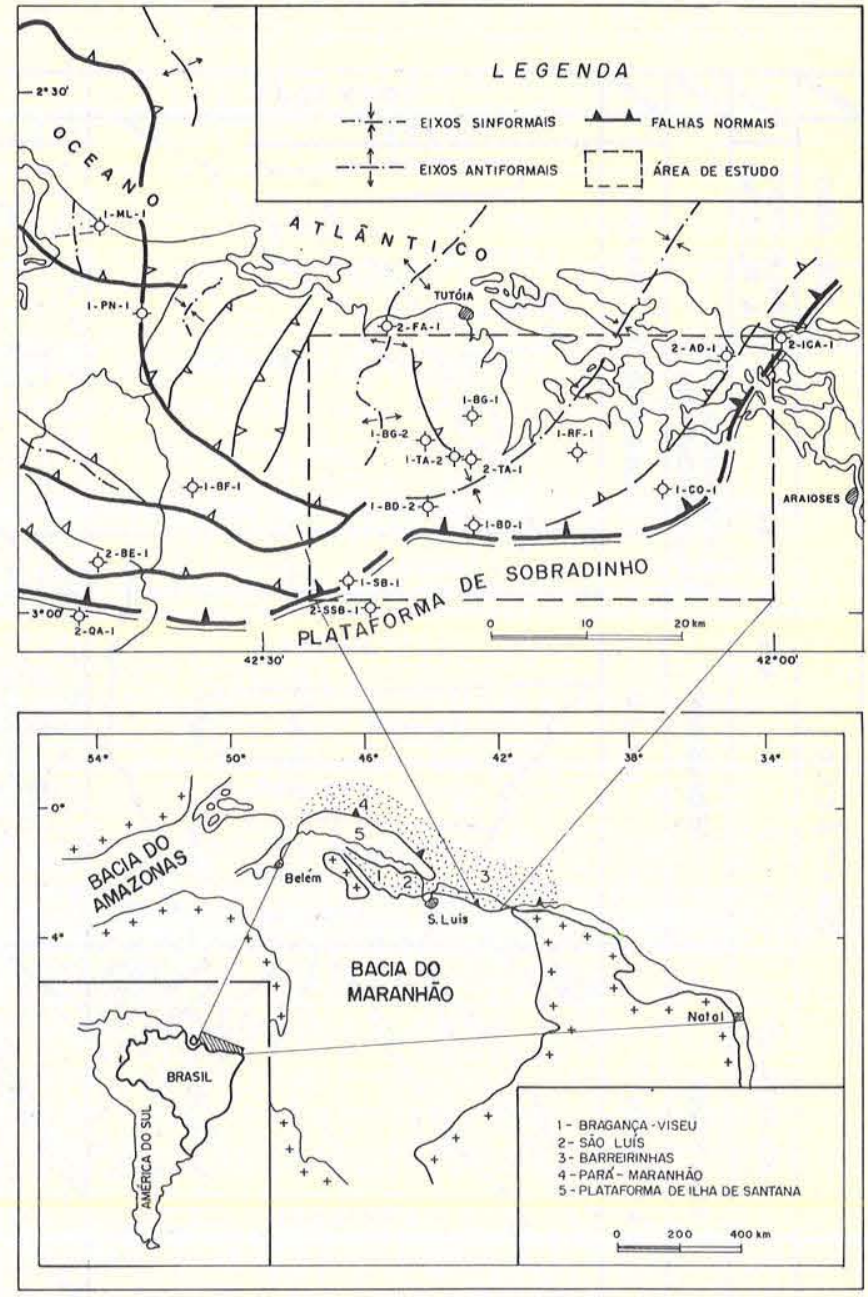

Figura 1 - Mapa de localização da Bacia de Barreirinhas e arcabouço estrutural de sua porção leste 
três grupos já existentes (Fig. 2). O Grupo Canárias passou a ser constituído então por cinco formações, denominadas Arpoador, Bom Gosto, Tutóia, Barro Duro e Sobradinho.

A Formação Bom Gosto, objeto deste estudo, restringe-se principalmente à porção leste e centro-sul da bacia, onde se sobrepõe discordantemente ao embasamento Pré-Cretáceo e concordantemente à Formação Arpoador. Os sedimentos Bom Gosto estão dispostos na forma de leques e exibem geralmente os horizontes A, B e D da clássica seqüência de Bouma (1962). Várias estruturas sedimentares foram observadas, entre elas estruturas hidrodinâmicas como turboglifos e marcas de ranhura; estruturas deformacionais flamiformes; camadas convolutas, gradacionais normais e inversas. Rodrigues et al. (1969) caracterizaram a Formação Bom Gosto como tendo sido depositada por correntes de turbidez em águas relativamente rasas ao longo da Plataforma de Sobradinho e em águas mais profundas ao longo do declive desta mesma plataforma. Como modelo deposicional foi então proposto aquele do tipo turbiditos proximais no sentido de Walker (1967). A ocorrência de foraminíferos planctônicos e radiolários nos folhelhos intercalados aos arenitos evidencia um ambiente marinho para a deposição da Formação Bom Gosto.

MÉTODOS Foram selecionados sete poços, dos quais foram coletadas 116 amostras a partir dos testemunhos de sondagem. Essas amostras, coletadas em intervalos irregulares, foram inicialmente impregnadas com epóxi azul e as lâminas delgadas, tingidas com uma solução de alizarina mais ferrocianeto de potássio (Dickson 1966). As análises modais se basearam na contagem de 300 constituintes por lâmina, com a malha de contagem estabelecida de acordo com a seleção e a granulometria da amostra. Para a caracterização e a quantificação dos poros, empregaram-se os critérios estabelecidos por Schmidt \& McDonald (1979b) e Pittman (1979), contando-se cerca de 200 poros por lâmina.

A identificação dos argilominerais foi realizada por difração de raio-X (amostras de granulação $<2 \mu$ orientadas) pela comparação do material seco ao ar, saturado com etilenoglicol e aquecido a $500^{\circ} \mathrm{C}$ por uma hora.

Algumas amostras foram examinadas com o microscópio eletrônico de varredura (MEV) para identificar minerais autigênicos, principalmente argilominerais, e para determinar melhor suas relações texturais.

As análises granulométricas a partir de lâminas delgadas foram efetuadas em 20 amostras e baseadas na medição dos eixos maiores aparentes de 100 grãos de quartzo monocristalino por lâmina. Esta quantidade é suficiente para se obter uma visão geral da distribuição granulométrica (Carver 1971). A utilização de grãos de quartzo monocristalino deveu-se, sobretudo, à resistência que este constituinte apresenta à corrosão diagenética.

RESULTADOS OBTIDOS Minerais Detríticos A Formação Bom Gosto, na área leste da bacia, é em geral caracterizada por apresentar camadas de arenitos cinza-claros

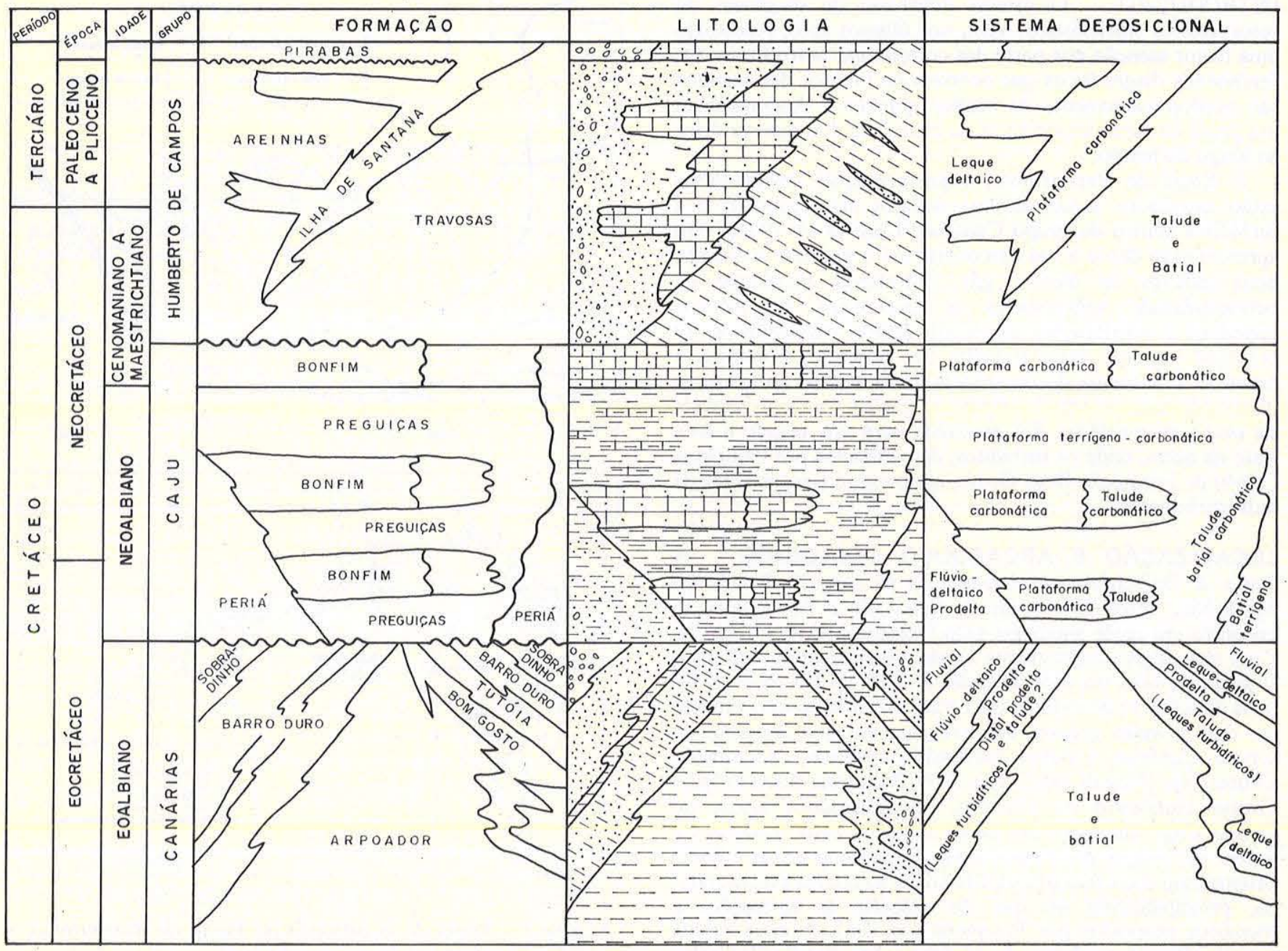

Figura 2 - Coluna estratigráfica da Bacia de Barreirinhas (adaptado de Figueredo et al. 1982) 
e esbranquiçados, intercalados com siltitos, folhelhos e diamictitos de cores cinza e preta. Os arenitos, com espessuras variáveis de centímetros a metros, são de granulação média e texturalmente submaturos a imaturos no sentido de Folk (1974). Apresentam, de uma maneira geral, características uni e bimodais, com diâmetros médios variando de 1,42 a 2,22 $\phi$ (areia média e fina) e seleção de 0,5 a 1,03 (bem a pobremente selecionado). O arredondamento dos grãos, embora mascarado pela corrosão diagenética, é bastante variado com partículas subangulosas e subarredondadas.

A composição mineralógica média dos arenitos da Formação Bom Gosto (Tab. 1) mostra $41,7 \%$ de quartzo, $23,6 \%$ de feldspato, $10,8 \%$ de fragmentos de rocha e $4,3 \%$ de minerais micáceos mais a clorita.

Tabela 1 - Composição média (\%) dos arenitos da Formação Bom Gosto na área leste de Barreirinhas

\begin{tabular}{lcccccccc} 
Pogos & 2-TA-1 & 1-TA-2 & 1-BG-1 & 1-BG-2 & 2-AD-1 & 1-BD-2 & 1-SB-1 & Média \\
\hline $\begin{array}{l}\text { Número } \\
\text { de amostras }\end{array}$ & 50 & 3 & 15 & 5 & 17 & 4 & 6 & 14 \\
Quartzo & 42,5 & 46,7 & 42,2 & 42,6 & 34,5 & 43 & 40,5 & 41,7 \\
Plagioclásio & 1,4 & 1 & 0,8 & 0,2 & tr. & 0,5 & 0,7 & 0,6 \\
K-feldspato & 23,2 & 27,4 & 23,4 & 23,4 & 17 & 28,7 & 17,3 & 23 \\
Frag. de rocha & 10,8 & 10 & 8,6 & 9,2 & 18 & 10,2 & 9,2 & 10,8 \\
Micas & 3,7 & 4 & 6,5 & 5 & 2,2 & 4,7 & 4,2 & 4,3 \\
Poros & 3,9 & 2 & 5 & 4,4 & 3,2 & 2,5 & 0,8 & 3,1 \\
Carbonatos & 8,9 & 2,3 & 8,2 & 8,8 & 18 & 7,2 & 21,2 & 10,6 \\
Caulinita & 1,9 & 5 & 2,2 & 2 & 5,1 & 2 & 3,3 & 3 \\
Matriz & 1,7 & - & 0,5 & 2,2 & tr. & tr. & tr. & 0,6 \\
Outros & 2 & 1,6 & 2,6 & 2,2 & 2 & 1,2 & 2,8 & 2 \\
\hline
\end{tabular}

O quartzo é o mineral mais abundante e se apresenta sob a forma de grãos mono e policristalinos, com extinção variando de reta a fortemente ondulante em ambos os casos. Os grãos de caráter monocristalino predominam, contudo os policristalinos são também abundantes. Estes últimos são geralmente compostos de dois a cinco indivíduos e alguns demonstram que foram submetidos a uma forte deformação, evidenciada por limites individuais geralmente não muito nítidos e forte extinçăo ondulante.

O feldspato é predominantemente do tipo potássico, ocorrendo subordinadamente plagioclásio. Apresenta-se sob diversas condições de preservação, de grãos inalterados (microclínio principalmente) a grãos severamente degradados. Entre as alteraçöes observadas, ocorrem predominantemente dissolução e substituição (Prancha 1-A, B, C).

Os fragmentos de rocha são bastante variados, abrangendo os seguintes tipos em freqüência decrescente: rochas graníticas, metamórficas, sedimentares e vulcanitos. Os fragmentos de rocha metamórfica são predominatemente de xistos, com presença de cristais de granada em alguns deles. Os fragmentos de rochas sedimentares são principalmente folhelhos, arenitos finos e calcários. Em alguns testemunhos, os fragmentos de folhelhos formam brechas intraformacionais com clastos cujos tamanhos chegam a atingir mais de $3 \mathrm{~cm}$. No poço 2-AD-1-MA em particular, observa-se a presença de fósseis entre os quais se destacam equinodermas, gastrópodes, pelecípodes e algas (Prancha 1-F).

A moscovita é o filossilicato mais abundante. Ocorrem ainda, subordinadamente, biotita e clorita. As micas são comumente alteradas: a biotita para clorita (Prancha 3-C) e a moscovita para illita e/ou caulinita.

Os minerais pesados presentes são principalmente turmalina, granada, zircão, anfibólio (?) e minerais opacos. A turmalina se apresenta em formas subarredondadas e prismáticas, sendo predominantemente de coloração esverdeada, A granada é comumente de cor rosada (almandina) e mostra formas bastante irregulares devido à substituição e dissoluçâo causada pela diagênese. Os zircōes sāo pouco freqüentes e em geral levemente arredondados.

A proporção de matriz é baixa, em média $0,6 \%$, com valores máximos em torno de $19 \%$, geralmente encontrados em arenitos com muitos fragmentos líticos esmagados, relacionados portanto à pseudomatriz (Prancha 1-D). A matriz é composta predominatemente por illita, clorita, quartzo, feldspato e opacos.

Quando classificados, utilizando-se o sistema de Pettijohn et al. (1973), os arenitos estudados da Formação Bom Gosto incluem $88 \%$ de arcósios, $7 \%$ de litarenitos, $3 \%$ de subarcósios e $2 \%$ de arenitos sublíticos (Fig. 3). Esta classificação, entretanto, nâo leva em consideraçã̉o os efeitos significativos causados pela diagênese, como dissolução e substituição de diversos grãos instáveis. A composição original destes arenitos deve ser, portanto, considerada mais feldspática e mais lítica.
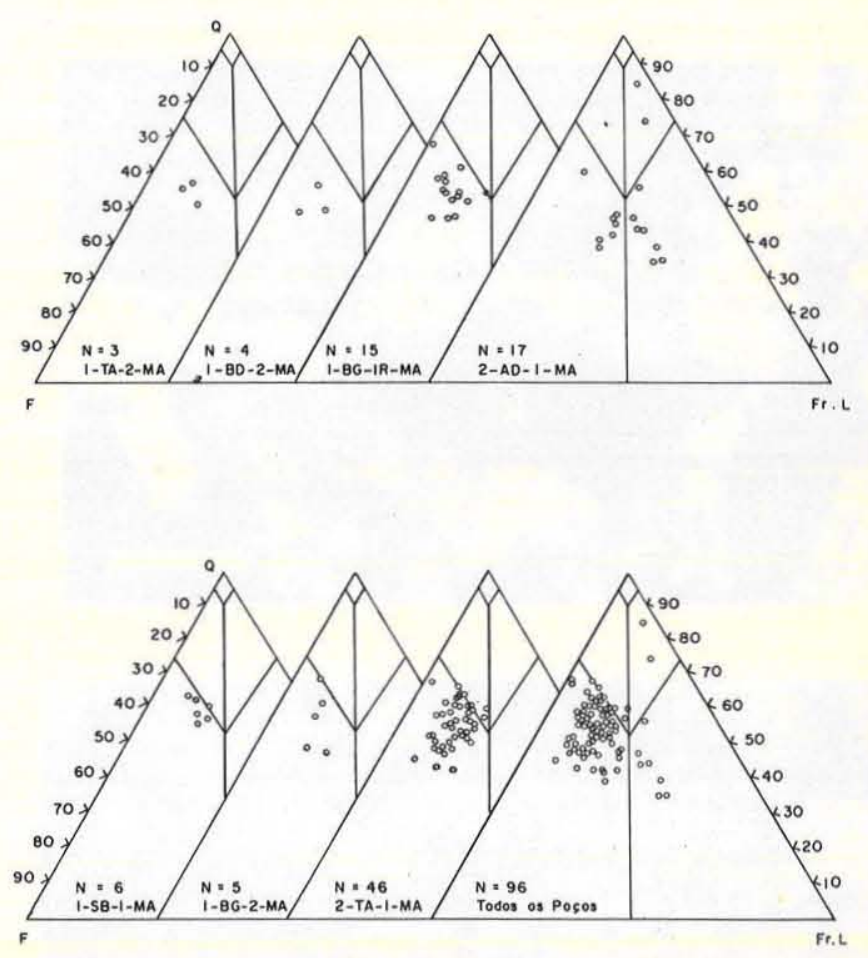

Figura 3 - Classificação dos arenitos da Formação Bom Gosto na área leste da bacia segundo Pettijonh et al. (1983). $Q=$ quartzo; $F=$ feldspatos; Fr. $L=$ fragmentos líticos; $N=$ número de amostras estudadas

Proveniência Os minerais pesados e os fragmentos de rocha observados nos arenitos da Formação Bom Gosto indicam que rochas graníticas, metamórficas, vulcânicas e sedimentares atuaram como principais fontes dos sedimentos. O transporte dos grãos até a bacia ocorreu, provavelmente, sob condiçōes de clima semi-árido (Petri 1983, Lima 1983), o que preservou de certa forma os minerais de uma alteração intempérica significativa. Torna-se evidente, pela interpretação tectônica da composição dos arenitos segundo Dickinson (1985), que o "embasamento do bloco continental soerguido" desempenhou um papel fundamental como área-fonte dos arenitos da Formação Bom Gosto (Fig. 4). Para este tipo de interpretação, contudo, é necessário utilizar a composição original dos arenitos e corrigir a freqüência dos constituintes segundo a metodologia de Gazzi \& Dickinson (Zuffa 1985). 

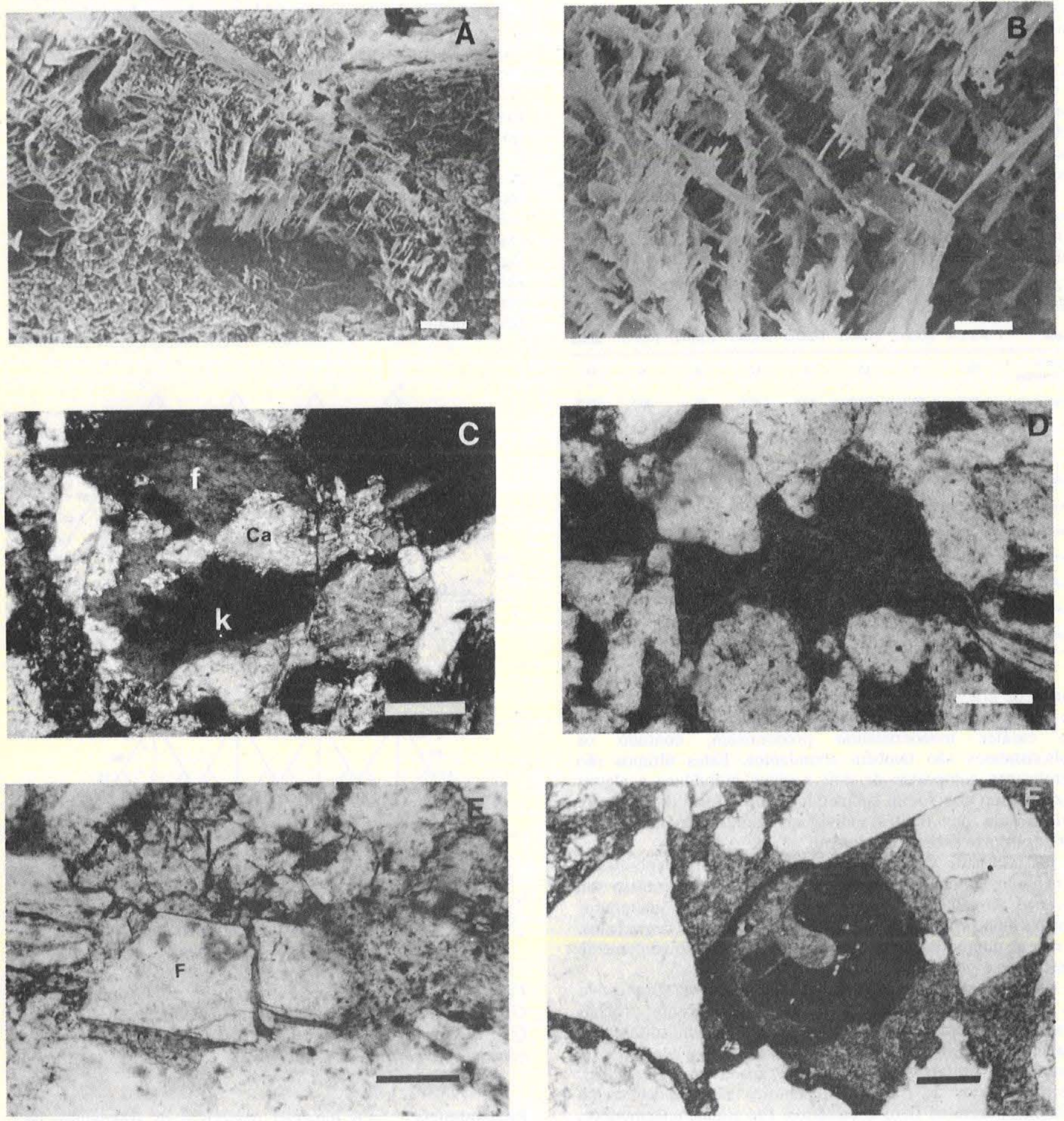

Prancha 1 - A. Feldspato intensamente solubilizado. Notar o aspecto alveolar e a microporosidade desenvolvida. MEV; Barra = $37 \mu$; poço: 1-BG-1-Ma; prof. 1.838, $2 \mathrm{~m}$. B. Detalhe da foto A. MEV; Barra $=7 \mu$. C. Grão de feldspato $(f)$ parcialmente substituído por carbonato $(\mathrm{Ca})$. Notar ao centro a caulinita $(k)$ preenchendo poro secundário. Barra $=100 \mu ; N x ;$ poço 2-TA-1-MA; prof. $2.695 \mathrm{~m}$. D. Fragmento pelítico esmagado formando pseudomatriz. Barra = $100 \mu$; N/l; poço 2-Ta-1-Ma; Prof. $2.695 \mathrm{~m}$. E. Feldspato $(F)$ fráturado formando porosidade secundária. Barra $=100 \mu ;$ N//; poço 2-AD-1-MA; prof. 1.324 m. F. Resto de gastrópode em arenito grosso fortemente cimentado por calcita. Barra $=300 \mu ; N / / ;$ poço 2-AD-1-MA; prof. $1.281 \mathrm{~m}$

PRODUTOS DIAGENÉTICOS Entre os fatores que influem na diagênese têm-se os seguintes: temperatura, pressão, mineralogia da fração detrítica, composição das águas intersticiais, fácies sedimentares associadas, tectônica, clima e tempo. Com tantas variáveis, as reações diagenéticas representam um complexo campo de estudo envolvendo uma larga gama de processos interligados, que incluem a compactação mecânica e química, a precipitação de cimentos, bem como a dissolução e substituição de minerais detríticos e autigênicos.

A compactação mecânica dos sedimentos é causada principalmente pelo soterramento e seu principal efeito é a redução da porosidade. Entre os vários mecanismos que atuam neste sentido, têm-se os seguintes: rotação e empacotamento 


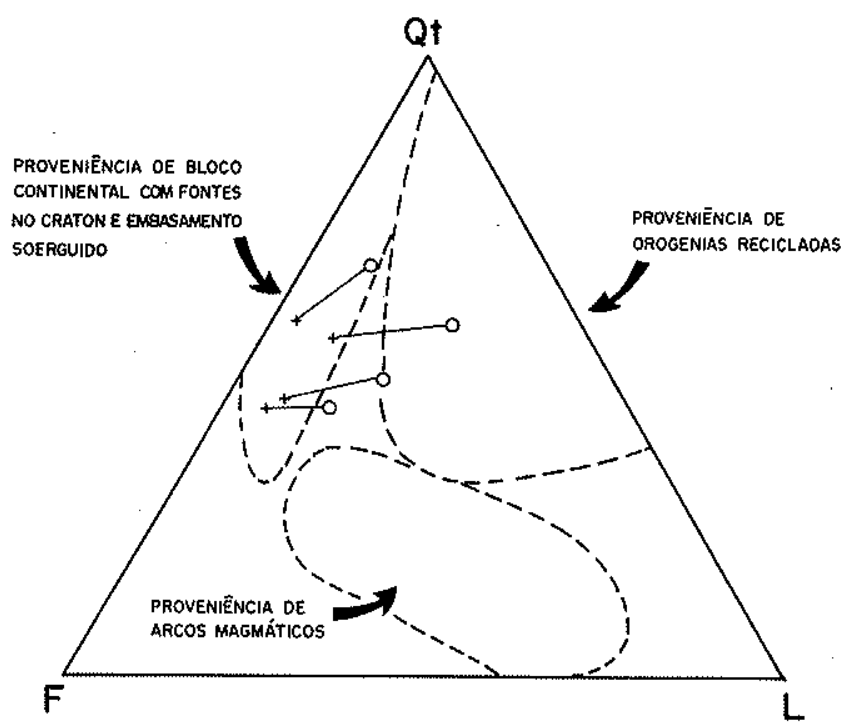

Figura 4 - Diagrama triangular QtFL segundo Dickinson (1985) mostrando a composição diagenética atual (círculos) de 4 arenitos representativos da Formaçäo Bom Gosto e a sua composição deposicional estimada e normalizada (cruzes) segundo o método de Gazzi-Dickinson (Zuffa 1985). Qt $=$ quartzo total; $F=$ feldspatos; $L=$ fragmentos liticos

denso dos grăos, deformação de grăos com comportamento dúctil e fraturamento de partículas rígidas. As micas e os fragmentos de rochas são os constituintes que mais comumente preservam evidências de compactação mecânica. Em casos de forte deformação plástica, alguns fragmentos podem dar origem a pseudomatriz, no sentido de Dickinson (1970). Quando o grăo apresenta um comportamento rígido, as fortes pressôes podem resultar em fraturamento.

A compactaçáo química ou dissolução por pressão tem sua origem nas pressóes localmente elevadas, que ocorrem nos contatos entre os grăos (pressão litostática). Uma das feições mais comuns da dissolução por pressão é a formação de estilblitos em rochas carbonáticas e microestilblitos em arenitos. A dissolução por pressão resulta numa perda de volume e porosidade, podendo o material dissolvido ser removido da formação ou precipitado dentro da mesma, sob a forma de cimentos que crescem homoaxialmente sobre a superfície dos grâos (Prancha 2-A, B, E).

A evidencia petrográfica para o reconhecimento da dissoluçåo por pressão é obtida pela avaliação da natureza e quantidade de contatos entre os gráos (Taylor 1950). Entretanto, isto só é possível em arenitos nos quais os contornos dos grăos sejam facilmente perceptiveis. Nos arenitos da Formação Bom Gosto, esse tipo de avaliação não póde ser realizada devido a intensa corrosáo causada pelo cimento carbonático. Apenas poucos microestilólitos, contatos suturados e côncavo-convexos foram notados como feições da compactação química. Mais freqüentemente perceptiveis são as feições de compactaçäo mecânica, tais como micas encurvadas entre os grãos mais rígidos do arcabouço, grăos fraturados e fragmentos líticos esmagados entre os grãos mais rígidos (Pracha 1-D, E).

Duas fases de fraturamento ocorreram nos arenitos da Formação Bom Gosto. A primeira precedeu a cimentaçāo carbonática e é pouco expressiva. Está representada por grấos do arcabouço que exibem fraturas preenchidas por cimento carbonático. A segunda, relativamente mais freqüente, foi posterior à dissolução do cimento carbonático e se caracteriza pelo colapso de "esqueletos" de feldspato. Ao contrário da primeira fase, resulta em redução de porosidade.

A cimentação, substituição e dissolução são processos comuns durante a diagênese dos arenitos. Podem modificar significativamente sua composiçăo e textura original causando, portanto, profundas variaçöes em suas propriedades petroffisicas.

Nos arenitos da Formação Bom Gosto, uma complexa seqüência de cimentações, substituições e dissoluçöes (descarbonatização principalmente) teve lugar. Os principais minerais neoformados são: quartzo, feldspato, calcita ferrosa e năo-ferrosa, dolomita ferrosa e não-ferrosa, ankerita, caulinita, illita, illita/esmectita, anatásio e pirita.

O quartzo ocorre em duas geraçöes distintas: a. sob a forma de sobrecrescimentos homoaxiais e $b$. diminutos cristais individualizados. Os sobrecrescimentos precederam a cimentação carbonática (carbonatização), sendo perceptíveis por uma linha de "sujeira" que separa os crescimentos secundários dos grãos. Os cristais individualizados, prismáticos, são nitidamente posteriores à descarbonatização. Ocorrem no interior de poros secundários e têm comprimento entre 5 e $10 \mu$ (Prancha 2-B, E, F, G). Entre os vários processos responsáveis pelo suprimento de sílica aos arenitos, os seguintes, aparentemente, atuaram durante a diagênese da Formação Bom Gosto: 1 . dissolução por pressão de grãos de quartzo; 2. substituiçăo de feldspatos por calcita; e 3 . caulinização e dissolução de feldspatos. Junto a esses processos, mais diretamente ligados aos arenitos, poderiam ter atuado também reaçôes nos folhelhos intercalados, tais como dissolução de grãos e alteração de argilominerais.

Semelhante ao quartzo, o feldspato autigênico ocorre como crescimento secundario de composição sódica e potássica sobre os plagioclásios e os feldspatos potássicos, respectivamente. Ocorre também sob a forma de albita tardia, posterior à descarbonatização. Nos plagioclásios, os sobrecrescimentos acompanham, geralmente, os planos de geminação dos grấos e se mostram suscetíveis à corrosão pelo cimento carbonático. A albita tardia, que cresce nos poros intragranulares de feldspatos, exibe agregados colunares de cristais complexamente geminados (Prancha 2-C e D). Foram observados, tambem, cristais de albita tardia inclusos em quartzo autigênico de segunda geração (Prancha 2-C). Muito embora os feldspatos autigênicos não sejam quantitativamente expressivos, sua presença nos arenitos fornece importantes informações acerca da natureza geral dos processos diagenéticos, principalmente no tocante à composição das aguas de formação, a partir das quais eles precipitam. Para a formação de feldspatos em rochas sedimentares, são necessárias condições geológicas especiais, como: temperatura acima de $60^{\circ} \mathrm{C}$ águas intersticiais levemente alcalinas e enriquecidas em $\mathrm{K}^{+}$e $\mathrm{Si}^{4+}$ (McBride 1985). Os elementos necessários a formação dos feldspatos provêm, principalmente, da hidrólise e da dissoluçăo de minerais menos estáveis. A sílica deve estar ligada a uma ou mais das fontes anteriormente citadas. Quanto aos demais elementos, poderiam ser fornecidos por fragmentos líticos, grãos de feldspatos de composição intermediária e mesmo pelas soluções intersticiais (águas de formação) (Pettijohn et al. 1973).

O cimento cabonático merece um destaque especial por ser o mais abundante. Ocorre sob a forma de cristais espáticos, assumindo por vezes caráter poiquilotópico. Geralmente está preenchendo poros de origem primária ou aparece corroendo e/ou substituindo grāos do arcabouço, de preferência de feldspatos (Pranchas 1-C e 4-A, B). Os principais carbonatos observados foram: calcita ferrosa e năo-ferrosa, dolomita ferrosa e nẫo ferrosa e subordinadamente ankerita. A calcita năo-ferrosa apresenta um "zoneamento" irregular, com o nácleo constituído de calcita e as bordas de calcita ferrosa. A dolomita, que substitui parcialmente a calcita, mantém o mesmo "zoneamento". A ankerita, embora de difícil distinção da dolomita ferrosa, ocorre sob a forma de diminutos cristais romboedrais no interior de poros de origem secundária, 

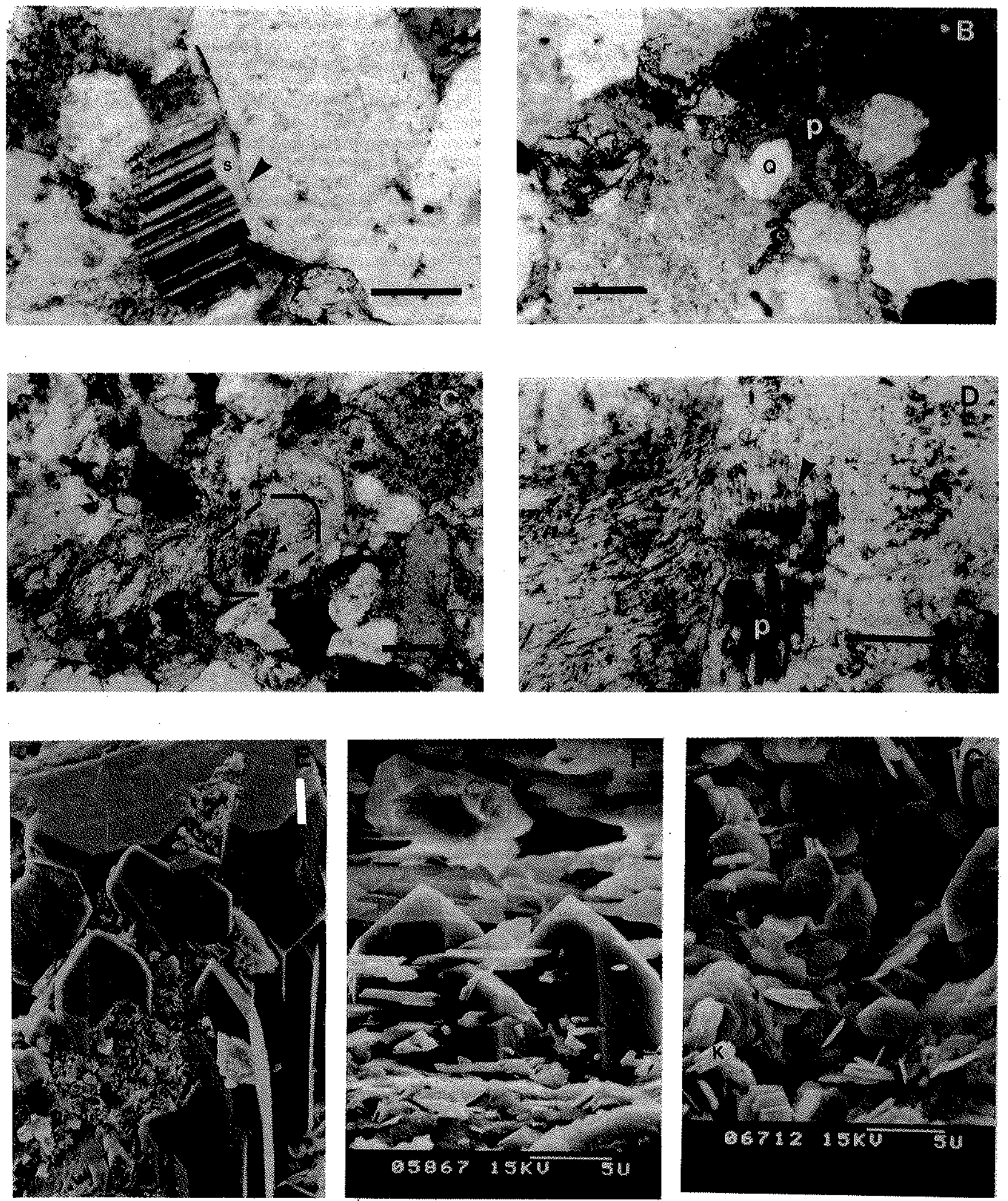

Prancha 2 - A. Sobrecrescimento de quartzo (s). Notar a tênue linha de contorno do grão (seta). Barra $=100 \mu ; N x ;$ poço 2 AD-1-MA; prof. $1.324 \mathrm{~m}$. B. Quartzo autigênico de segunda geração (Q), com faces prismáticas bem desenvolvidas, crescendo no interior de um poro secundário $(p)$. Barra $=100 \mu ; N x+\lambda / 4 ;$ prof. $1.324 \mathrm{~m}$. C. Feldspato com porosidade intragranular (seta). Barra $=200 \mu ; N x+\lambda / 4 ;$ poso 2-AD-1-MA; prof. $1.324 \mathrm{~m}$. D. Detalhe da foto $C$ mostrando o poro intragranular ( $p$ ) com a presença de albita autigênica tardia (seta). Barra $=100 \mu ; N / /$. E. Quartzo autigênico $(Q)$. Notar a presença de clorita $(C l)$ entre os cristais de quartzo. MEV; Barra $=12 \mu$; poço 1-BG-1-MA; prof. 1.744,4 m. F. Quartzo de segunda geração $(Q)$ com vários cristais de clorita autigênica inclusos (seta). MEV; Barra $=5 \mu ;$ poço 1-BG-1-MA; prof. $1.703 \mathrm{~m}$. G. Cristais de quartzo (Q) individualizados no interior de poro secundário. Notar ainda a presença de clorita $(C l)$ e caulinita $(k)$. MEV;Barra $=5 \mu ;$ poço $1-B D$. IMA; prof. $2.069 \mathrm{~m}$ 

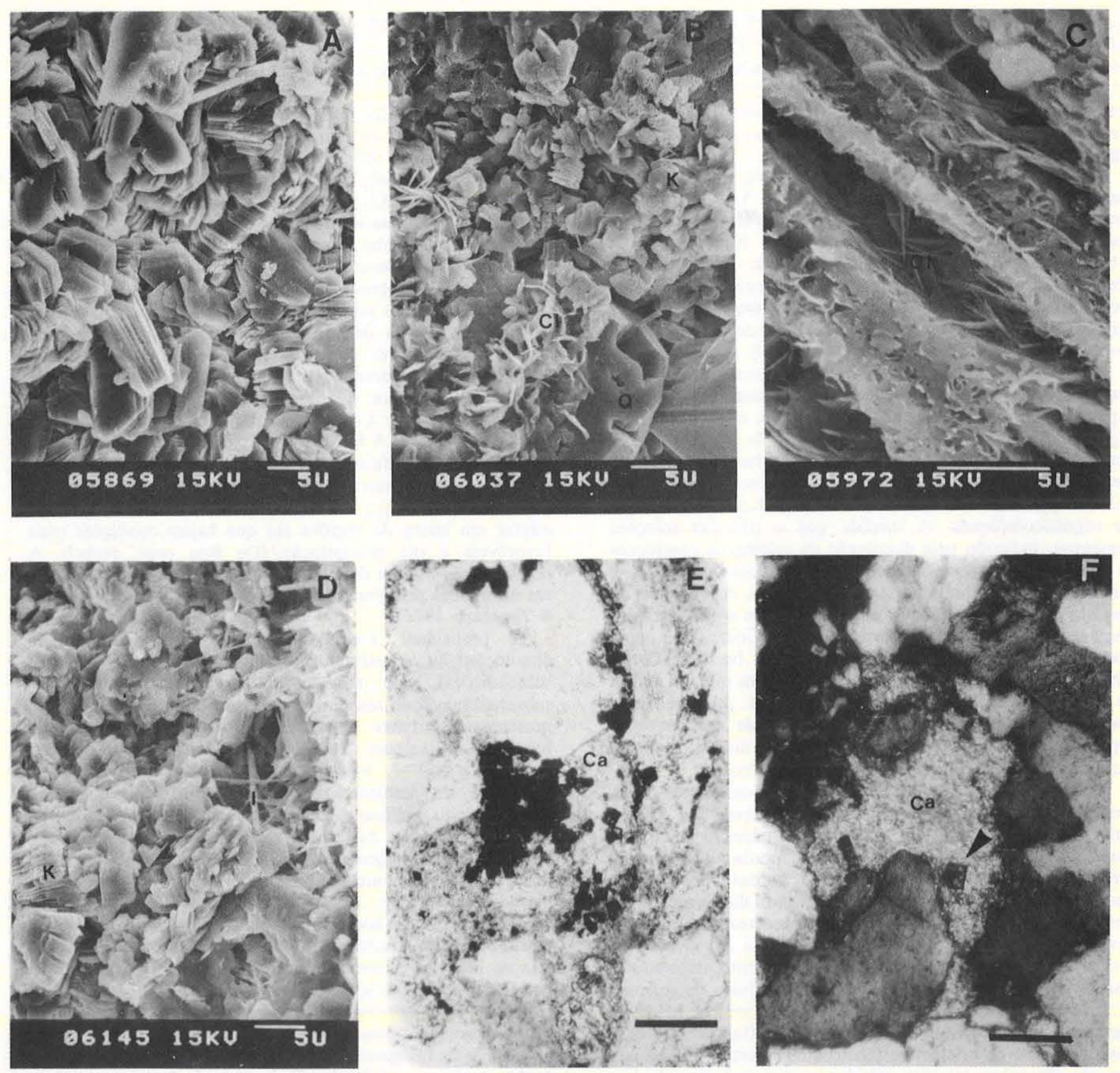

Prancha 3-A. "Livretos" de caulinita preenchendo poro secundário. MEV;Barra $=5 \mu$; poço 1-BG-2-MA; prof. 1.703 m. B. Clorita $(\mathrm{Cl})$ forrando poro secundário. Notar ainda a presença de caulinita $(k)$ e quartzo de segunda geração $(Q)$. $M E V ; B a r r a=5 \mu$; poşo 1-TA-1-MA; prof. 2.401,3 m. C. Alteração de mica, provavelmente biotita para clorita. Notar também que a clorita (Cl) desenvolve-se melhor entre os planos de clivagem. MEV; Barra $=5 \mu ;$ poço 1-BG-2-MA; prof. 1.704,2 m. D. Illita autigênica (I) ligando "livretos" de caulinita ( $k$ ). MEV; Barra $=5 \mu ;$ poço 1-TA-2-MA; prof. $2.403 \mathrm{~m}$. E. Agregado escuro de cristais de anatásio. Notar que alguns cristais estão inclusos no cimento carbonático $(\mathrm{Ca})$ enquanto outros aparecem isolados no interior do poro secundário (p). Barra $=100 \mu ; N x+\lambda / 4 ;$ poço 2-AD-1-MA; prof. $1.324 \mathrm{~m}$. F. Anatásio autigênico tabular incluso em cimento carbonático (Ca). Barra $=100 \mu ; N X ;$ Poço 2-TA-1-MA; prof. 2.474,4 m

geralmente próximos a cristais de biotita alterada.

A origem do cimento carbonático está relacionada, muito provavelmente, a fenômenos diagenéticos que ocorrem nos folhelhos supra e subjacentes, representados pelas formaçöes Tutóia e Arpoador. O crescente soterramento e conseqüente aumento na pressão e temperatura devem ter afetado significativamente os argilominerais e a matéria orgânica contidos nos folhelhos, o que provavelmente influenciou sobremaneira a natureza dos fluidos intersticiais dos arenitos no sentido de elevar a pressão de $\mathrm{CO}_{2}$ e tamponar o $\mathrm{pH}$ pela ação de ácidos orgânicos. Essas reaçỏes favorecem a precipitação de cimentos carbonáticos (Surdam \& Crossey 1985). A origem do "zoneamento", também observado por Evamy (1969) e Bruhn (1985), não é bem conhecida. Bruhn (op. cit.), de forma especulativa, considera que o processo de substituição de silicatos por difusão iônica favorece a precipitação da calcita não-ferrosa por ser uma fase mais ordenada. A calcita ferrosa, por sua vez, deve corresponder a uma cimentação e/ou substituição em condições mesodiagenéticas mais avançadas, nas quais o $\mathrm{Fe}^{2+}$ teria sua origem ligada à "illitização" do interestratificado illita/esmectita, que durante o processo libera quantidades 
significativas de $\mathrm{Fe}^{2+}$ e $\mathrm{Mg}^{2+}$ (Boles \& Franks 1979). A dolomitização observada nos arenitos da Formação Bom Gosto estaria também relacionada ao fenômeno que deu origem à calcita ferrosa, só que em condiçöes mais profundas. Para Zenger (1983 apud Bruhn 1985), os fatores inibidores de formação da dolomita são bastante reduzidos em temperaturas mais elevadas.

Dos argilominerais autigênicos presentes, a caulinita é o mais abundante. Seu tamanho, superior a $5 \mu$, facilita seu reconhecimento sob o microscópio petrográfico. Ocorre de duas formas no arenitos da Formação Bom Gosto: 1 . substituindo pseudomorficamente grãos de feldspato e 2 . preenchendo parcial ou totalmente poros de origem secundária. A caulinita mostra além disso dois hábitos principais: $a$. agregados de placas na forma de "livretes" e $b$. agregados vermiculares (Prancha 3-A, B, D). A relação entre o desenvolvimento de porosidade secundária e o preenchimento de poros secundários por caulinita pode ser explicada, segundo Curtis (1983) e Surdam et al. (1984), da seguinte maneira: soluçōes intersticiais de caráter ácido, geradas em profundidade pela degradação termocatalítica do querogênio, teriam sido capazes de dissolver e transportar grandes quantidades de metais, mesmo o alumínio, na forma de organocomplexos. $\grave{A}$ medida que o pH das soluçőes aumentou, induzido pela dissolução da calcita, os complexos se tornaram provavelmente instáveis, condicionando a precipitação de caulinita no interior do poros. A tendência do cimento de caulinita diminuir em volume com a profundidade observada nos arenitos da Formação Bom Gosto, bem como nos arenitos "Ericson" do Neocretáceo da bacia de Green River, EUA (Edman \& Surdam 1984), sugere que em ambos os casos o pH das soluçōes intersticiais provavelmente aumentou como resultado da dissolução de carbonatos e separação dos fluidos da fonte de acidez, em direção às partes estratigraficamente superiores nas duas seqüências.

A clorita é o segundo argilomineral em importância. Ocorre como "franjas" sobre a superfície livre dos grãos e também como produto de alteraçâo de minerais micáceos. Esta alteração é evidenciada pela perda na cor de birrefringência, principalmente nas bordas dos grãos, acompanhadas, freqüentemente, por um alargamento em forma de leque. As "franjas" de clorita crescem em geral perpendicularmente à superfície dos grãos e em direģaõ ao centro dos poros secundários. Estão geralmente associadas a cristais euedrais diminutos de quartzo autigênico de segunda geração (Pranchas 3-B, C e 2-G). As análises por MEV de algumas amostras revelaram que, onde as "franjas" são bem desenvolvidas, os cristais autigênicos de quartzo de segunda geração são aparentemente inibidos ou pouco desenvolvidos. Por outro lado, observam-se diminutas plaquetas de clorita inclusas nos cristais de quartzo autigênico de segunda geração, o que sugere uma origem anterior ou mesmo concomitante da clorita em relação ao quartzo. Outra observação importante é a coexistência da clorita com a caulinita. Este fato poderia significar, segundo Boles \& Franks (1979), que a reação mineral responsável pelo crescimento de clorita autigênica ocorreu da seguinte maneira:

$\mathrm{Fe}^{+2}+\mathrm{Mg}^{+2}+2 \mathrm{H}_{2} \mathrm{O}+$ caulinita $\rightarrow$ clorita $+4 \mathrm{H}^{+}$

Os cátions $\mathrm{Fe}^{2+}$ e $\mathrm{Mg}^{2+}$ teriam sido originados da desidratação dos folhelhos, onde a illitização da esmectita libera tais elementos.

A illita e o interestratificado illita/esmectita ocorrem em quantidades bastante reduzidas. Geralmente são produtos de alteração diagenética de constituintes detríticos ou precipitados químicos. A illita ocorre no interior de poros secundários na forma de "pontes", interligando cristais de caulinita (Prancha 3-D). Uma das possíveis reações para explicar sua precipitação é a seguinte:
$\mathrm{K}^{+} \mathrm{Al}(\mathrm{OH})_{3}+\mathrm{H}_{4} \mathrm{SiO}_{4} \rightarrow$ illita $+\mathrm{H}_{2} \mathrm{O}+\mathrm{H}^{+}$

A principal fonte de íons seria o feldspato potássico (Moraes 1985).

Entre os cimentos menos freqüentes estão a pirita e o anatásio. A pirita é encontrada no interior de poros secundários sob a forma de agregados de minerais com forma framboidal. Sua origem está ligada a ambientes levemente ácidos, devido ao $\mathrm{CO}_{2}$ gerado provavelmente nos folhelhos. $\mathrm{O}$ anatásio se apresenta em tamanho variado, predominando os cristais com tamanho em torno de $10 \mu$ de comprimento (Prancha 3-E,F). Ocorrem de diversas maneiras nos arenitos: 1. inclusos em sobrecrescimentos de quartzo de primeira geração, 2. inclusos no cimento carbonático, 3. como cristais isolados no interior de poros secundários e 4 . associados na forma de outgrowth com minerais opacos, principalmente leucoxênio. Há, aparentemente, pelo menos três geraçőes de anatásio: $a$. anterior à cimentação por sílica de primeira geração, $b$. anterior à cimentação carbonática e $c$. posterior à descarbonatização. A fonte de titânio é atribuída à degradação de minerais titaníferos detríticos, como ilmenita, biotita, anfibólio etc. Assim como o alumínio, o titânio forma organocomplexos que o tornam suficientemente móvel para migrar em busca de regiōes em que hajam condiçőes mais favoráveis a sua precipitação (De Ros com. verbal). A neoformação intensa do anatásio em sedimentos carbonosos e em horizontes pedogenéticos corrobora esta hipótese (Hering \& Zimmerle 1976).

A porosidade secundária resulta principalmente da dissolução de constituintes instáveis (grãos, cimentos e substituiçōes), que reagem com as águas intersticiais subsaturadas com respeito a uma ou mais fases minerais presentes (Bjorlykke 1984). Este tipo de porosidade pode formar-se a qualquer instante durante a história diagenética de uma rocha: 1. antes do soterramento efetivo, sob a influência do ambiente deposicional, portanto dentro do regime eodiagenético; 2 . a qualquer profundidade de soterramento acima da zona de metamorfismo, isto é, durante o regime mesodiagenético; e 3. durante a telodiagênese (Schmidt \& McDonald 1979a). Entretanto, é durante a mesodiagênese que os maiores volumes de porosidade secundária são gerados, principalmente pela dissolução de constituintes carbonáticos de origem autóctone e alóctone (Hayes 1979). A porosidade secundária pode ser ainda gerada por fraturamento de grãos e rochas, e ainda por contração de constituintes do arcabouço dos arenitos.

A dissolução mesodiagenética da calcita e em menor proporção de feldspatos nos arenitos é devida à ação de $\mathrm{CO}_{2} \mathrm{e}$ ácidos orgânicos resultantes da degradação da termocatalítica do querogênio nos folhelhos, a partir dos quais os ácidos são transportados para os arenitos. Este processo de migração é favorecido pelas reações de desidratação nos folhelhos. Carothers \& Kharaka (1978) verificaram que em alguns campos de petróleo os ácidos carboxílicos presentes em temperaturas de $80^{\circ} \mathrm{C}$ a $120^{\circ} \mathrm{C}$ atingem concentraçöes de até $5.000 \mathrm{ppm}$ nas águas de formação, o que representa um potencial suficiente para dissolver carbonatos e/ou aluminossilicatos (Surdam et al. 1984). Esses mesmos autores demonstraram que os ácidos orgânicos são capazes de elevar significativamente a solubilidade do alumínio pela complexação, tornando-o suficientemente móvel para ser removido do arcabouço.

Os arenitos da Formação Bom Gosto apresentam feições típicas de porosidade secundária (Prancha 4-B, C, D). Tanto seus constituintes detríticos, quanto os autigênicos, mostram nítidos sinais de dissolução. Entre os grãos do arcabouço, os principais atingidos foram os feldspatos, principalmente plagioclásio, seguidos de fragmentos líticos de origem granítica. Mais fortemente que os grãos, foram afetados os constituintes autigênicos, sobretudo o carbonato na forma de 

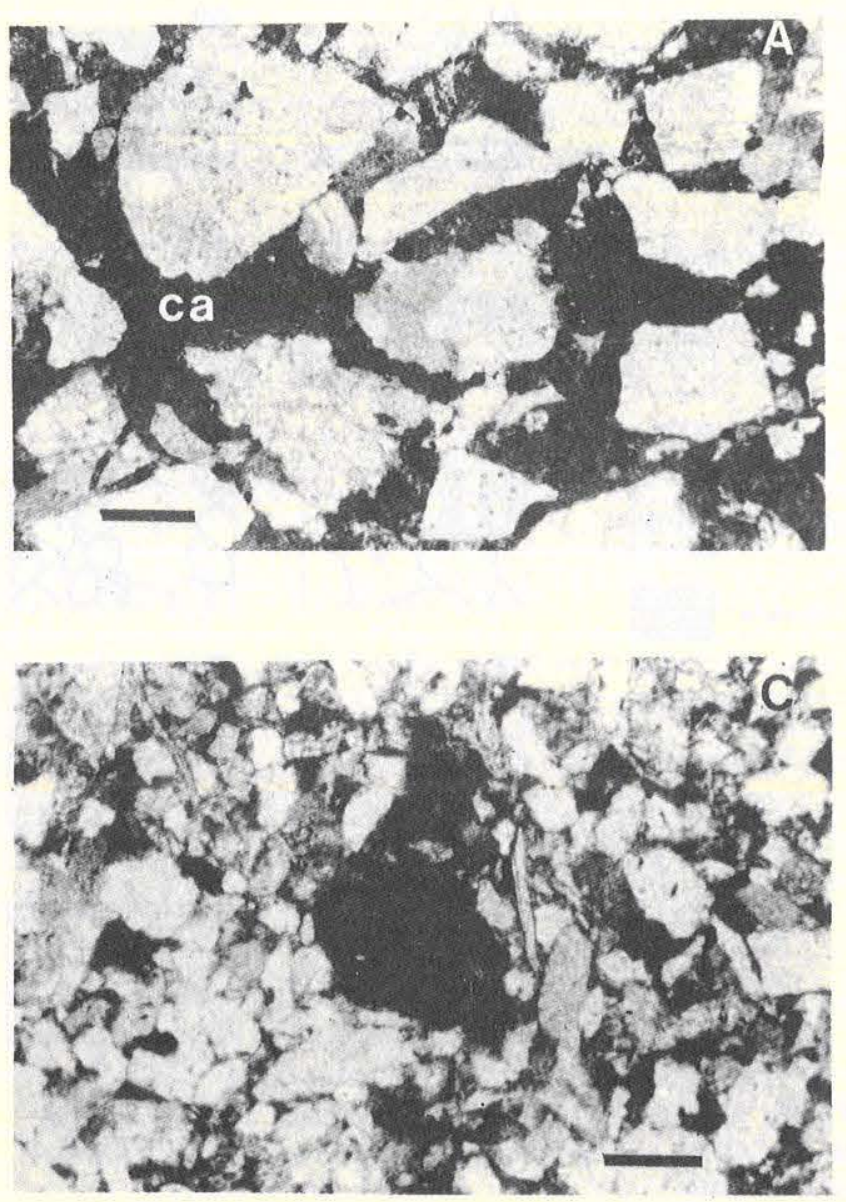

Prancha 4 - A. Forte corrosão dos grãos de arenito pelo cimento carbonático $(\mathrm{Ca})$, que se traduz também por um arcabouço mais aberto que o original. Barra $=300 \mu ; N / /$; poço 2-AD-1-MA; prof. $1.565 \mathrm{~m}$. B. Aspectos da porosidade secundária (p) por dissolução parcial do cimento carbonático $(\mathrm{Ca})$. Barra $=300 \mu ;$ N/l poço 2-AD-1-MA; prof. 1.528,7 m. C. Poro agigantado resultante da dissolução de cimento e grãos do arcabouço. Barra $=300 \mu ;$ NI/; poço 1-BG-1-MA; prof. $1.743,8 \mathrm{~m}$. D. Carbonato $(\mathrm{Ca}$ ) corroído e caulinita autigênica (K) preenchendo o espaço gerado pela corrosão. MEV; Barra $=5 \mu ;$ poço 2-TA-1-MA; prof. $2.733,7 \mathrm{~m}$

cimento e substituição. A dissolução parcial ou total dos vários constituintes e subordinadamente o fraturamento geraram diversos tipos de porosidade secundária, cuja identificação baseou-se nos critérios adotados por Schmidt \& McDonald (1979a) e Shanmugam (1985). São eles principalmente: $a$. grãos corroídos; $b$. restos de cimentos e substituições; $c$. zonas adjacentes com porosidade diferentes; $d$. moldes de grãos; $e$. heterogeneidade no empacotamento; $f$. poros agigantados; $g$. grãos fraturados; $h$. poros intraconstituintes; $i$. poros alongados. A avaliação do sistema poroso comprovou a ubiqüidade da porosidade secundária em quase todas as amostras estudadas. Dezenove amostras representativas dos cinco poços estudados tiveram seus poros quantificados com base em suas posições dentro do arcabouço textural e em várias de suas características geométricas. Segundo os esquemas apresentados por Pittman (1979) e Schmidt \& McDonald (1979b), quatro categorias principais foram discriminadas: $A$. porosidade de dissolução óbvia; $B$. porosidade intergranular regular; $C$. microporosidade; e $D$. porosidade de fraturamento (Fig. 5).

A porosidade de dissolução óbvia (A) foi dividida em seis classes denominadas A1, A2, A3, A4, A5 e A6. A porosidade tipo A1 é formada por poros intergranulares amplificados que
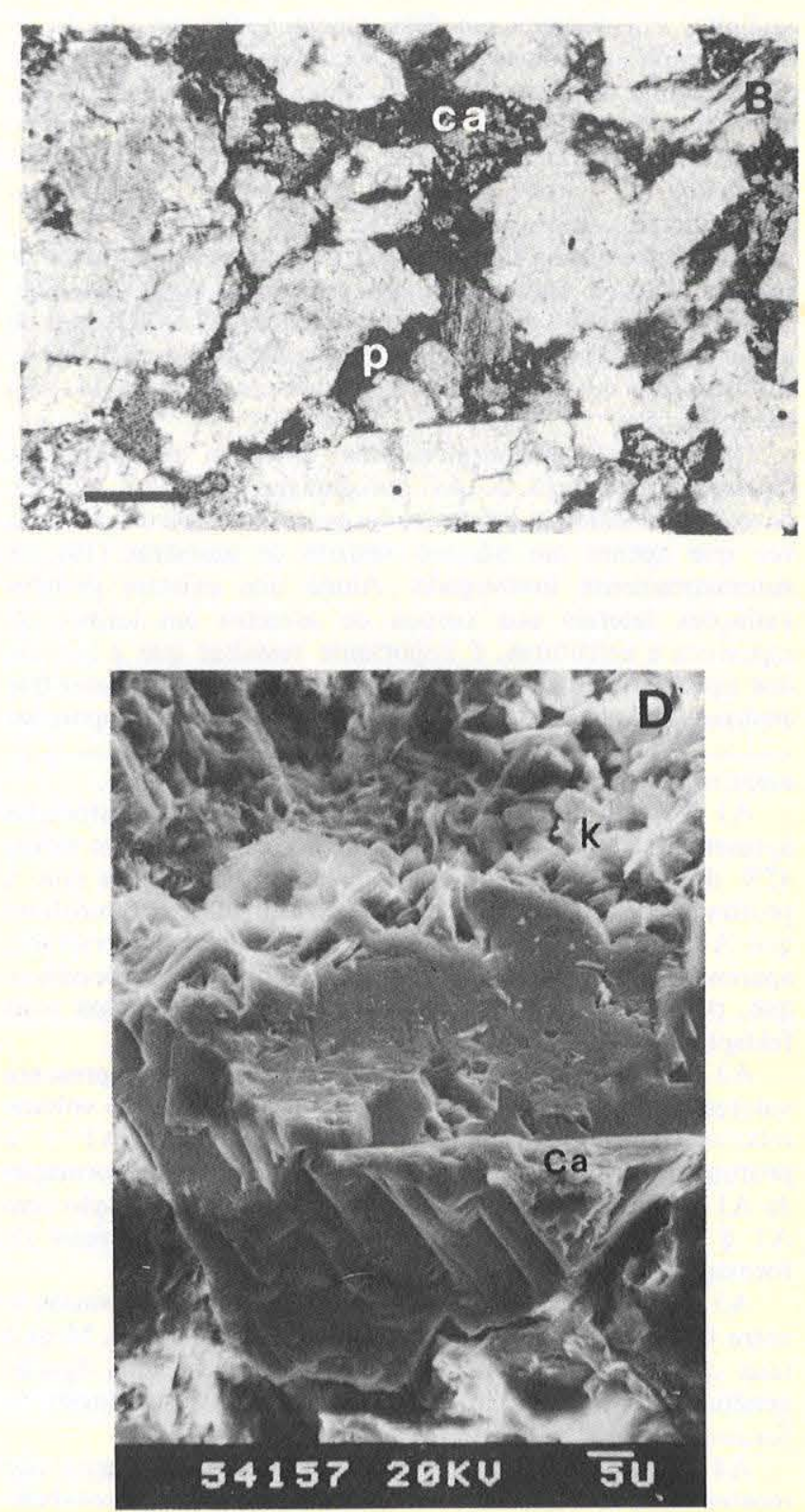

se originam a partir da dissolução total do cimento corrosivo. Mostram contornos irregulares e é comum encontrar-se em seu interior restos de grãos bastante corroídos. A2 é semelhante a A1; difere apenas por apresentar restos de cimentos. A3 são poros que se originam da dissolução parcial do cimento "não-corrosivo"; diferem de A2 por apresentar as bordas dos poros "lisas" ou retilíneas. A4 são poros intragranulares, formados a partir da dissolução parcial ou total de minerais de substituição, e ocorrem de preferência em feldspatos. A5 é formada por poros móldicos e se origina a partir da dissolução total de grãos e/ou susbtituições instáveis. Por último, A6 é formada por poros "agigantados", gerados a partir da dissolução de grãos e/ou substituições; seu diâmetro deve atingir pelo menos 1,2 vezes o diâmetro dos grãos adjacentes (Schmidt \& Mcdonald 1979 b).

A segunda categoria (B), denominada porosidade intergranular regular, é semelhante à porosidade primária. Possui bordas lisas, tem pequenas dimensões e apresenta formato geralmente triangular. Contudo, a origem secundária para esses poros não deve ser descartada. Neste caso, o cimento não seria agressivo e teria sido totalmente dissolvido.

A terceira categoria $(\mathrm{C})$ corresponde à microporosidade e é observada, principalmente, entre os agregados de cristalitos de 
caulinita. Foi dividida em duas subcategorias em função da forma como este mineral é encontrado no arcabouço textural dos arenitos: C1 corresponde a "manchas" de caulinita que preenchem parcial ou totalmente os poros de origem secundária do tipo $\mathrm{A} 1$ ou $\mathrm{A} 2$; e $\mathrm{C} 2$ refere-se a grãos de feldspatos, parcial ou totalmente substituídos pseudomorficamente por caulinita.

A quarta e última categoria (D), denominada porosidade de fraturamento, é formada, como o próprio nome diz, pelo microfraturamento de grảos ou da própria rocha. Ocorre de preferência em grãos de feldspato, que são mais suscetíveis ao fraturamento devido aos planos de fraqueza apresentados pela clivagem.

Uma análise quantitativa dos tipos de porosidade é mostrada na tabela 2. As porcentagens obtidas, todavia, devem ser encaradas apenas como valores de orientação, uma vez que apenas um número restrito de amostras (19) foi sistematicamente investigado. Ainda que existam grandes variaçōes laterais nos corpos de arenitos em termos de espessura e estruturas, é importante ressaltar que a maioria dos tipos de porosidade está presente em todas as amostras analisadas. Apenas A3, A6, C2 e D ocorrem em proporçōes menores. A figura 6 apresenta a matriz de correlação calculada entre os diversos tipos de porosidade e a profundidade.

A1 é o tipo mais abundante; $68 \%$ das amostras estudadas apresentam valores superiores a $40 \%$, perfazendo em média $45 \%$ do volume total de porosidade. As correlações com a profundidade, o cimento carbonático e o feldspato mostram que A1 aumenta em volume com a profundidade crescente, aparentemente à custa da dissolução do cimento carbonático, que, por sua vez, mostra uma preferência por rochas mais feldspáticas.

A2 é o terceiro tipo de porosidade dominante e apresenta valores bastante irregulares, variando de $1 \%$ a $39 \%$ do volume relativo de porosidade. As correlaçōes com A1 e a profundidade mostram que $\mathrm{A} 2$ decresce à custa da formação de $\mathrm{A} 1 \mathrm{e}$ à medida que aumenta a profundidade. A relação com A1 é evidente já que A2 representa o estágio inicial de formação da porosidade $\mathrm{A} 1$.

A3 tem em média valores pouco expressivos, variando entre $0 \%$ e $19,5 \%$ do volume relativo de porosidade. Mostra uma correlação negativa com $\mathrm{A} 1$, que sugere uma ligação genética, ou seja, A3 é provavelmente uma fase incial na formação de A1.

A4 está ligada intimamente aos feldspatos. Portanto nảo mostra boas correlaçōes com os demais tipos de porosidade. Sua distribuição é de certa forma regular, atingindo em média $8,5 \%$ da porosidade.

A5 exibe valores muito baixos, variando de $0 \%$ a $7 \%$. As correlaçōes positivas com A1 e B induzem à interpretação de que este tipo de porosidade se formou a partir da dissolução de cimentos que substituíam os grâos.

A6 é o tipo de porosidade de dissolução menos freqüente. Ocorre esporadicamente em valores bastante reduzidos.

A porosidade tipo $\mathrm{B}$, quarta categoria em abundância, varia de $0,5 \%$ a $19,5 \%$ do volume total da porosidade, perfazendo em média $7,8 \%$. Sua correlação positiva com A1 e A5 sugere que a mesma aumente em volume com a dissolução do cimento carbonático.

C1 é o segundo tipo de porosidade mais abundante e atinge em média $17,8 \%$. Cerca de $47 \%$ das amostras apresentam valores acima de $20 \%$ do volume relativo de porosidade. Mostra uma forte correlação negativa com A1, A 5 e B, o que confirma a origem autigênica para a caulinita. Além disso, tende a diminuir com a profundidade crescente.

$\mathrm{A}$ porosidade $\mathrm{C} 2$ não é muito freqüente; atinge em média o valor relativo de $1,5 \%$. Não apresenta correlação com nenhum outro tipo de porosidade, o que é justificável pois está ligada a fenômenos de substituição pseudomórfica de feldspatos por caulinita.
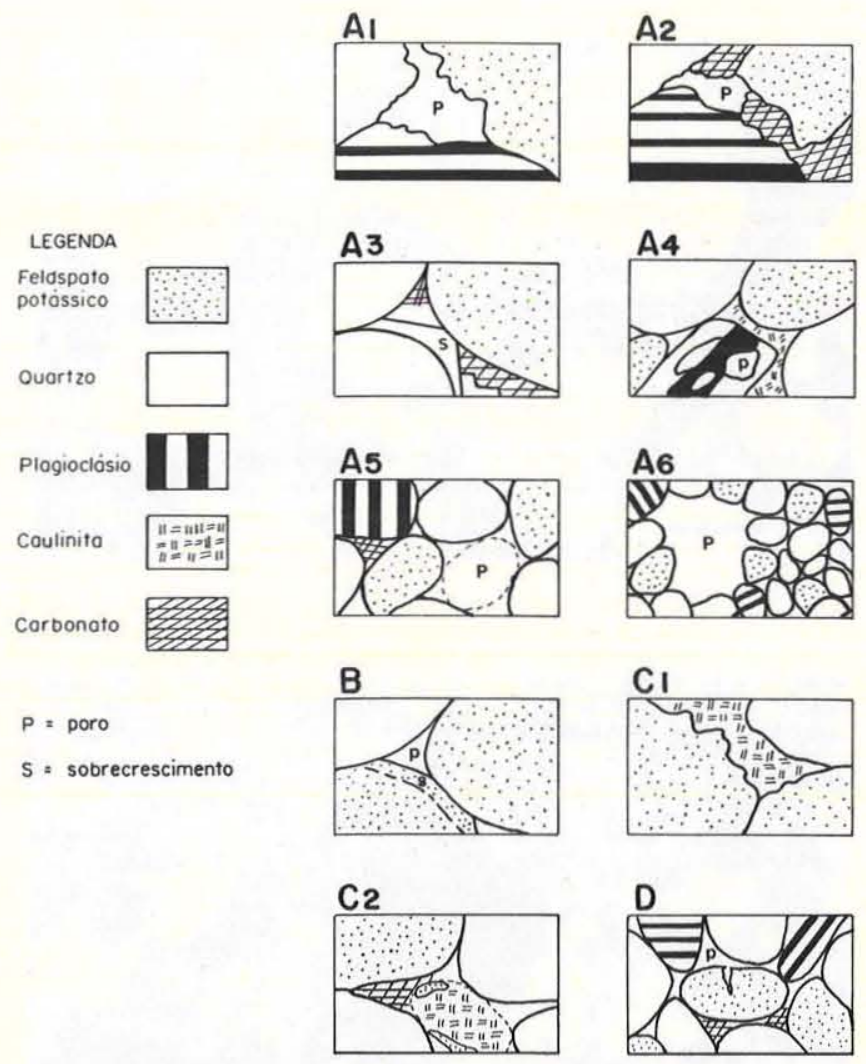

Figura 5 - Tipos de porosidade secundária. Modificado a partir de Pittman (1979) e Schmidt \& McDonald (1979). Explicaçóes no texto

Tabela 2 - Análise semiquantitativa dos tipos de porosidade

\begin{tabular}{lrrrrrrrrrr} 
Amostras & $\mathbf{A 1}$ & $\mathbf{A 2}$ & $\mathbf{A 3}$ & $\mathbf{A 4}$ & $\mathbf{A 5}$ & $\mathbf{A 6}$ & $\mathbf{B}$ & $\mathbf{C 1}$ & $\mathbf{C 2}$ & $\mathbf{D}$ \\
\hline L-5159 & 19,0 & 28,0 & 9,0 & 5,5 & 2,5 & - & $\mathbf{6 , 0}$ & 28,0 & $\mathbf{1 , 5}$ & $\mathbf{0 , 5}$ \\
L-5160 & 25,5 & 26,5 & 3,5 & 9,5 & 1,0 & - & 3,0 & 27,5 & 1,5 & 2,0 \\
L-5162 & 11,0 & 32,5 & 9,0 & 8,5 & 2,0 & - & 10,0 & 24,5 & 0,5 & 1,5 \\
L-5163 & 31,0 & 23,5 & 4,0 & 5,0 & 4,5 & - & 4,0 & 21,5 & 2,0 & 4,5 \\
L-5164 & 13,0 & 39,0 & 1,0 & 8,0 & 0,5 & - & 1,5 & 31,5 & 4,0 & 1,5 \\
L-3592 & 68,5 & 1,5 & - & 9,0 & 4,5 & 0,5 & 8,0 & 6,5 & 0,5 & 1,0 \\
L-3593 & 56,5 & 4,0 & 0,5 & 9,5 & 3,5 & - & 14,0 & 11,0 & - & 1,0 \\
L-3588/1 & 48,0 & 4,0 & 1,0 & 10,0 & 5,0 & - & 10,0 & 16,0 & 6,0 & - \\
L-3589 & 50,5 & 6,0 & - & 9,5 & 2,0 & - & 7,5 & 20,5 & 3,5 & 0,5 \\
L-4001 & 48,0 & 10,0 & 0,5 & 8,5 & 1,5 & - & 6,0 & 23,0 & 2,5 & - \\
L-4002 & 43,0 & 11,0 & 1,5 & 13,5 & 2,0 & - & 9,5 & 17,5 & 1,0 & 1,0 \\
L-3619 & 21,5 & 16,0 & 0,5 & 9,5 & - & - & 3,5 & 47,0 & - & 2,0 \\
L-5105 & 55,0 & 7,5 & 1,5 & 5,5 & 5,5 & - & 19,5 & 4,0 & 1,0 & 1,0 \\
L-5111 & 43,5 & 14,5 & 3,5 & 5,5 & 5,0 & - & 10,5 & 14,5 & 2,5 & 0,5 \\
L-5112 & 65,0 & 4,5 & 0,5 & 8,5 & 4,5 & - & 11,0 & 5,5 & - & 0,5 \\
L-5121 & 50,5 & 4,0 & - & 8,5 & 7,0 & - & 19,5 & 8,0 & 1,5 & 1,0 \\
L-5141 & 72,0 & 3,0 & - & 10,5 & 6,0 & - & 5,5 & 3,0 & - & - \\
L-5143 & 70,0 & 1,0 & - & 7,5 & 4,5 & - & 3,0 & 11,5 & 0,5 & 2,0 \\
L-5152 & 60,0 & 10,0 & - & 10,0 & 1,5 & - & 0,5 & 17,5 & 0,5 & - \\
\hline
\end{tabular}

Obs.: Os símbolos A1, A2, A3, A4, A5, A6, B, C1, C2 e D podem ser identificados na fig. 5 .

A porosidade tipo $\mathrm{D}$, tal como $\mathrm{C} 2$, ocorre em valores muito baixos, em média $1,2 \%$. Não mostra correlações significativas com os demais tipos de porosidade.

A partir da análise do comportamento dos diversos tipos de porosidade com a profundidade, observa-se que as porosidades tipo A e B crescem em volume a maiores 
Prof. A1 A2 A3 A4 A5 A6 B

Prof. 1,00
A1 $0,75 \quad 1,00$
A2 $-0,68-0,92 \quad 1,00$
A3 $-0,53-0,68 \quad 0,71 \quad 1,00$
A4 $0,04 \quad 0,20-0,28-0,40 \quad 1,00$
A5 $0,54 \quad 0,61-0,57-0,18-0,27 \quad 1,00$
A6 -0,11 $0,30-0,24-0,16 \quad 0,06 \quad 0,14 \quad 1,00$
B $\quad 0,27 \quad 0,24-0,37-0,03-0,11 \quad 0,62 \quad 0,00 \quad 1,00$

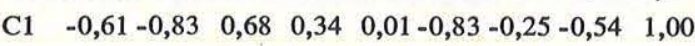
C2 $-0,32-0,27 \quad 0,17-0,02-0,09-0,04-0,16-0,06 \quad 0,18 \quad 1,00$
D $\quad-0,39-0,39 \quad 0,41 \quad 0,24-0,39-0,07-0,02-0,21 \quad 0,33-0,11 \quad 1,00$

Figura 6-Matriz de correlação entre os tipos de porosidade secundária e a profundidade

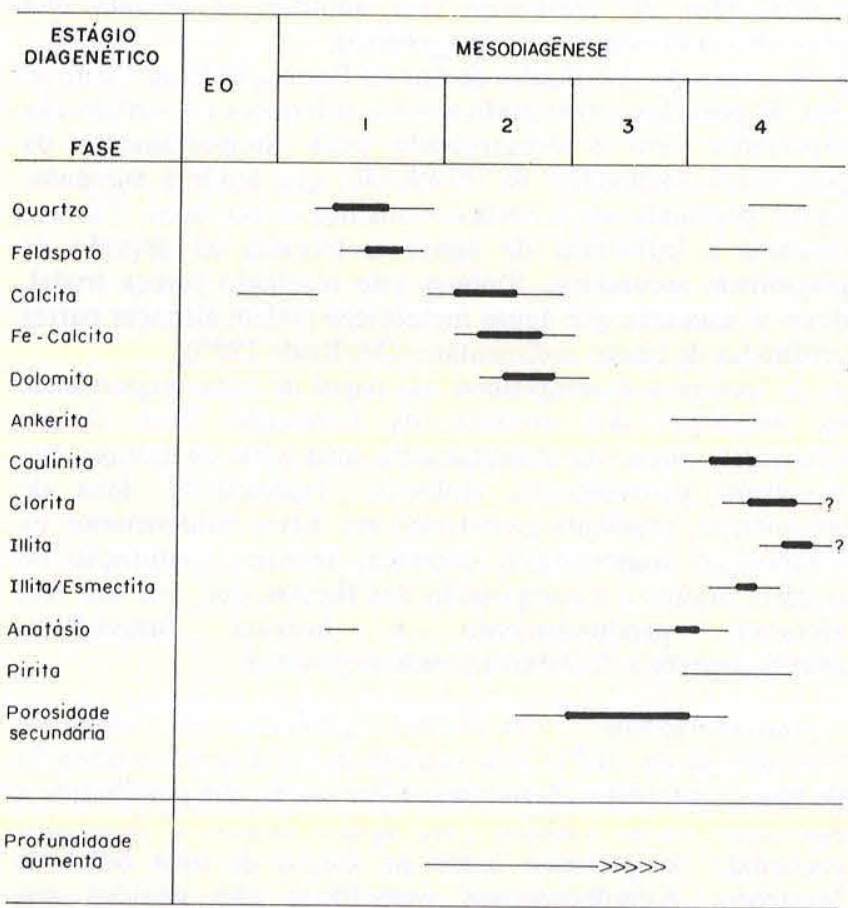

Figura 7 - Estágios diagenéticos da Formação Bom Gosto mostrando as principais fases de cimentação e dissolução dos constituintes texturats

profundidades, indicando um aumento progressivo na disssolução do cimento carbonático nesta direção. Tal fato descarta a possibilidade da influência de águas meteóricas na dissolução dos constituintes do arcabouço e sugere que a dissolução do cimento carbonático tenha sido causada pela ação de soluções ácidas ascendentes, originadas provavelmente pelas reações orgânicas que se processaram nos folhelhos intercalados aos arenitos da Formação Bom Gosto e, talvez, naqueles subjacentes a esta formação (Arpoador, Codo?). A tendência observada da porosidade tipo $\mathrm{C} 1$, diminuir com a profundidade sugere que a caulinita seja mais estável a menores profundidades, talvez em função de mudanças no $\mathrm{pH}$ das soluções.
HISTÓRIA DIAGENÉTICA Os arenitos da Formação Bom Gosto apresentam uma complexa seqüência diagenética que pode ser dividida em quatro estágios (Fig. 7).

Estágio 1 Aqui se iniciou a compactação dos sedimentos, principalmente de origem mecânica, que produziu um rearranjo nos grãos do arcabouço e causou, em parte a deformação de minerais micáceos, bem como o esmagamento de fragmentos líticos de caráter dúctil. Ainda durante esta fase houve o fraturamento de grãos, principalmente os de feldspatos. Evoluindo para uma diagênese química - que propiciou o desenvolvimento de sobrecrescimentos de quartzo e feldspato sobre as superfícies livres dos grãos de mesma composição e em conseqüência desses processos mecânicos e químicos -, a porosidade sofreu uma redução significativa. Segundo Schmidt \& McDonald (1979a), este estágio inclui a eodiagênese e a mesodiagênese imatura.

Estágio 2 Predominância da diagênese química, na qual a carbonatização desempenhou o papel maior, reduzindo a porosidade existente. O cimento carbonático possui em parte caráter corrosivo, evidenciado pela substituição parcial ou total de grãos do arcabouço. Localmente, a calcita apresenta uma tẹtura poiquilotópica, e, em geral, mostra um "zoneamento" não muito regular, com o núcleo constituído de calcita e as bordas de calcita ferrosa. Ao final deste estágio ocorreu uma dolomitização parcial em condições profundas que manteve o "zoneamento". Este estágio corresponde à mesodiagênese semimatura de Schmidt \& McDonald (1979a).

Estágio 3 Caracteriza-se pela dissolução parcial e/ou total do cimento e substituições carbonáticas, que resultam na criação de porosidade secundária nos arenitos da Formação Bom Gosto. Além do cimento calcítico, os grãos do arcabouço mais fortemente atacados foram os feldspatos e fragmentos líticos de origem granítica. A dolomita se opôs à formação da porosidade secundária devido a sua maior estabilidade em relação à calcita. Este estágio é compatível ao estágio mesodiagenético maturo A de Schmidt \& McDonald (1979a).

Estágio 4 É caracterizado pela redução da porosidade secundária pelos processos químicos e mecânicos. Os principais processos químicos envolvidos foram a precipitação de argilominerais, principalmente caulinita, e cimentos de proporções menores, como pirita, quartzo, feldspato de segunda geração, ankerita e anatásio. Além da caulinita, foram observados ainda os seguintes argilominerais: clorita, illita e o interestratificado illita/esmectita. A redução da porosidade secundária por processos mecânicos deveu-se sobretudo ao colapso de estruturas alveolares de feldspatos. Foi aparentemente durante este estágio que houve a migração dos hidrocarbonetos, como evidencia a presença de vestígios de betume envolvendo delicadas estruturas de caulinita vermicular. De acordo com Schmidt \& McDonald (1979a), este estágio pode ser classificado como mesodiagênese matura $\mathrm{B}$.

A seqüência diagenética dos arenitos da Formação Bom Gosto mostra uma exceção: no poço 2-AD-1-MA, algumas amostras apresentam constituintes bioclásticos e uma cimentação carbonática eodiagenética. Os fósseis, como se comentou anteriormente, são característicos de ambiente marinho raso e, talvez, oriundos de alguma plataforma carbonática ainda não perfurada.

CONTROLES PRINCIPAIS DA DIAGÉNESE A diagênese dos arenitos é controlada por uma série de parâmetros que abrangem uma vasta escala, de flutuações 
locais na composição química das soluçōes intersticiais à tectônica de placas. Geralmente não é apenas um único fator o responsável pela sequiência diagenética, mas sim, diferentes fatores que interligados influenciam a diagênese. A evolução diagenética é fortemente determinada por fatores pré-soterramento como proveniência, ambiente deposicional e tectônica (dinâmica da bacia), que influenciam a composiçāo e textura dos sedimentos. Estas, por sua vez, governam as reações minerais e taxas de fluxos dos fluidos intersticiais (Hayes 1979).

A proveniência dos arenitos da Formação Bom Gosto está ligada, sobretudo, a rochas de composição granítica (embasamento soerguido), bem como às condições climáticas durante o Albiano, que propiciaram um elevado grau de instabilidade química para os arenitos. Isto favoreceu, conseqüentemente, sua intensa alteração diagenética.

Para Dickinson (1985), os soerguimentos do embasamento, limitados por falhas ao longo de cinturōes de rifte incipiente e falhas transformantes, fornecem areias de composição arcosiana, principalmente para bacias do tipo pull-apart.

Azevedo et al. (1984) caracterizaram a Bacia de Barreirinhas como tendo sido formada durante um regime tectônico transcorrente. A evidência mais importante é registrada pelo mapa de intensidade magnética, onde verifica-se sua delimitação côncava para norte e retilínea a NW e SE (plataformas de Ilha de Santana e Parnaíba, respectivamente). Esta configuração é encontrada principalmente nas bacias pull-apart tipo rômbicas em zonas de divergência de placas (Azevedo et al. 1985).

Além das carcterísticas estruturais e morfológicas, a Bacia de Barreirinhas apresenta um perfil de sistemas deposicionais típicos de bacias pull-apart modernas (cp. Dune \& Hempton 1984). Destacam-se entre as características principais as grandes espessuras nos pacotes sedimentares em relação ao tamanho da bacia; as elevadas taxas de sedimentação; os padrōes faciologicos assimétricos; a organização das fácies em conglomerados nas bordas falhadas; um sistema distal/ prodelta, talude e batial na parte central da bacia; o preenchimento predominante no sentido longitudinal; e, por fim, ciclos texturais que refletem as atividades tectônicas. Esses fatores influenciaram direta ou indiretamente a diagênese da Formação Bom Gosto.

No estágio inicial de formação da Bacia de Barreirinhas, a deposiçāo de sedimentos pelágicos e hemipelágicos, ricos em matéria orgânica (até turbiditos), ocorreu sob condições parcialmente redutoras e a maturação da matéria orgânica nas rochas geradoras de hidrocarbonetos deve ter sido encorajada pelo rápido soterramento e subsidência, tal como sugere Reading (1980) para as bacias do tipo pull-apart.

A taxa de sedimentação chegou a ser superior a 100 $\mathrm{cm} / 1.000$ anos durante o Albiano (Azevedo et al. 1985). Tal taxa de sedimentação foi produzida por uma rápida subsidência e, conseqüentemente, um elevado fluxo térmico foi entāo gerado devido à justaposição momentânea da Bacia de Barreirinhas com um spread center setentrional (Azevedo et al. op. cit.). O gradiente geotérmico na parte leste da bacia atinge valores superiores a $25^{\circ} \mathrm{C} / \mathrm{km}$, chegando de forma esporádica a $40^{\circ} \mathrm{C} / \mathrm{km}$, (Zembrusky \& Azevedo 1987). Tais condiçōes impingiram aos sedimentos da Formação Bom Gosto uma intensa alteração diagenética. A rápida subsidência e o conseqüente soterramento submeteram logo os sedimentos a uma forte compactação, quando então foram liberados volumes significativos de soluções, reduzindo a porosidade primária. As principais feiçőes químicas associadas a este regime são os diversos tipos de cimentos. A elevação seguinte da temperatura, em consęqüência do crescente soterramento provocou transformaçöes significativas nos argilominerais e na matéria orgânica. Os ácidos orgânicos, gerados anteriormente aos hidrocarbonetos, atuaram como solventes poderosos e tiveram a capacidade de mobilizar elementos como o alumínio na forma de compelxos (c.p. Surdam et al. 1984). Estas soluções, provavelmente, foram os principais responsáveis pela geração, manutenção e/ou destruição da porosidade secundária e minerais autigênicos (c.p. Carothers \& Kharaka 1978).

CONCLUSÕES 1. A diagênese dos arenitos da Formação Bom Gosto se processou num sistema químico aberto, em que é evidente a transferência de massa.

2. Os folhelhos adjacentes, juntamente com a matéria orgânica neles inclusa, sảo considerados como os principais responsáveis pela cimentação, substituição e dissolução dos constituintes do arcabouço dos arenitos, à medida que passaram pelo estágio mesodiagenético.

3. A migração dos fluidos ácidos na Formação Bom Gosto se deu de posiçōes estratigraficamente inferiores no sentido das superiores. Isto é demonstrado pelo comportamento da porosidade secundária de dissoluçâo, que tende a aumentar com a profundidade à custa do cimento carbonático. Tal fato descarta a influência de águas meteóricas na geração da porosidade secundária. Embora este resultado pareça trivial, deve-se salientar que águas meteóricas podem alcançar partes profundas de bacias sedimentares (McBride 1985).

4. A tectônica desempenhou um papel de suma importância na diagênese dos arenitos da Formação Bom Gosto. Controlou direta ou indiretamente uma série de fatores que envolvem proveniência, ambiente deposicional, taxa de subsidência, gradiente geotérmico etc. Estes influenciaram na composição mineralógica detrítica, textura, maturação de matéria orgânica e composição dos fluidos, que, por sua vez, afetaram produndamente a história diagenética, principalmente a de natureza mesodiagenética.

Agradecimentos Os autores agradecem ao Centro de Geociências da UFPa, pelo suporte material e pela utilização de seus laboratórios, bem como à Petrobrás, que possibilitou a realização deste trabalho pelo apoio técnico e financeiro concedido ao primeiro autor na forma de uma bolsa de Mestrado. Agradecimentos específicos são devidos aos geólogos Dr. Mário Caputo, Humberto Lima e Renato Azevedo, da Petrobrás/Denor; Joel C. de Castro e Luis F. de Ros, do Cenpes; e Arturo Garófalo, da UFPa, pelas discussões e contribuições. Os autores são gratos especialmente à geóloga Ana Maria Pimentel Mizusaki (Cenpes) e ao geoquímico Antônio Vaquera Vargas (UFPa), pela valiosa colaboração nas análises por microscopia eletrônica de varredura e pela ajuda computacional, respectivamente. Gostaríamos de agradecer ainda ao geólogo Adison M. de Oliveira pela leitura crítica do trabalho.

\section{REFERÊNCIAS BIBLIOGRÁFICAS}

ANDREIS, R.R. 1981. Identificación e importancia geologica de los paleosuelos. Porto Alegre, Editora da UFRGS, $67 \mathrm{p}$.

AZEVEDO, R.P. de; ROSSETTI, E.L.; NEPOMUCENंO FILHO, F.; CAPUTO. M.V. 1984. Origem e evolucāo tectono-sedimentar da Bacia de Barreirinhas. Belém, Petrobrás/Depex/Denor. 32 p. (Rel. Interno)

BJØRLYKKE, K. 1984. Formation of secondary porosity: How important is it? In: McDONALD, D. A. \& SURDAM, R. C. eds.
Clastic diagenesis. Tulsa. OK. Am. Assoc. of Petrol. Geol. p. 227-289. (Memoir 37)

BOLES, J.R. \& FRANKS, S.G, 1979. Clay diagenesis in Wilcox sandstones of southwest Texas: implications of smectite diagenesis on sandstones cementation. J.Sed.Petrol., 49(1):65-70.

BOUMA, A.H. 1962. Sedimentology of some flysch deposits. Amsterdam, Elsevier. 168 p.

BRUHN, C.H.L. 1985. Sedimentação e evolução diagenética dos 
turbiditos eocretáceos do Membro Gomo, Formação Candeias, no compartimento NE da bacia do Recôncavo (Bahia). Ouro Preto, 203 p. (Dissertação de Mestrado, Universidade Federal de Ouro Preto)

CAROTHERS, W.W. \& KHARAKA, Y.K. 1978. Aliphatic acid anions in oil field waters - implications for origin of natural gas. Amer. Assoc. Petrol. Geol. Bull., 62(12):2441-2453.

CARVER, R.E. 1971. Procedures in sedimentary petrology. London. Wiley. $653 \mathrm{p}$

CURTIS, C.D. 1983. A link between aluminium mobility and destruction of secondary porosity. Am. Assa. Petrol. Geol. Bull. 67:380-384.

DICKINSON, W. R. 1970. Interpreting detrital modes of graywacke and arkoses. J.Sed. Petrol., 40(2):695-707.

DICKINSON, W.R. 1985. Interpreting provenance relations from detrital modes of sandstones. In: ZUFFA, G. G. ed.Provenance of arenites, Dordrecht, D. Reidel Publ, p. 333-361. (Series C 148)

DICKSON, J.A.D. 1966. Carbonate identification and genesis as revealed by staining. J.Sed Petrol., 36:491-505.

DUNNE, L.A. \& HEMPTON, M.R. 1984. Deltaic sedimentation in the Lake Hazar pull-apart basin, south-eastern Turkey. Sedimentology, 31:401-412.

EDMAN, J.D. \& SURDAM, R.C. 1984. Diagenetic history of the Phosphoria Tensleep and Madison Formations. Tip Top Field. Wyomming. In: McDONALD, D.A. \& SURDAM, R.C. eds. Clastic diagenesis. Tulsa. OK. Am. Assoc. of Petrol. Geol. p. 317-347. (Memoir 37)

EVAMY, B.D. 1969. The precipitational environment and correlation of some calcite cements deduced from artificial staining. J. Sed. Petrol., 40:695-707.

FIGUEIREDO, A.M.F. TEIXEIRA, L; AMORIM, J, CARMINATTI, M. 1982. Projeto Barreirinhas, reavaliaçäo da bacia Cretácea - área terrestre e martitima. Belém. Petrobrás. Depex. 58 p. (Rel. Interno)

FOLK, R.L. 1974. Petrology of sedimentary rocks. Austin, Hemphill Pub. 182 p.

HAYES, J.B. 1979. Sandstone diagenesis - The hole truth. In: SCHOLLE, P.A. \& SCHLUGER, P.R. eds. Aspects of diagenesis. Tulsa, OK. Soc. of Economic Paleont. and Mineralogists. p. 127-135. (Special Publ. 26)

HERING, O. \& ZIMMERLE, W. 1976. Die Tiefbohrung Saar 1. Zusammenfassende Beschreibung der authigenen Minerale. Geol. Jb. A, 27:233-245.

LIMA, M.R. de. 1983. Paleoclimatic reconstruction of the Brazilian Cretaceous based on palynological data. Rev. Bras. Geoc., 13(4):233-228.

LIMA, H.P.; ROSSETTI, E.L.; PENA FILHO, W. 1985. Modelo das acumulaçōes de petróleo do campo de São João, bacia de Barreirinhas. In: SIMP. GEOL. da AMAZÔNIA, 2, Belém, 1985. Anais... Belém, SBG Núcleo Norte. v. 3, p. 239-253.

McBRIDE, E.F. 1985. Sandstone diagenesis. Tulsa, Amer. Assoc. Petrol. Geologists. 33 p. (AAPG Convention Short Course)

MORAES, M.A.S. 1985. Petrologia dos arenitos turbidíticos da bacio de Campos. Ouro Preto, 112 p. (Dissertaçảo de Mestrado, Universidade Federal de Ouro Preto)

MORAES, M.A.S. 1986. Reaçōes químicas na diagênese de arenitos.
In: CONGR. BRAS. GEOL., 34 Goiânia, 1986, Anais... Goiânia, SBG. v. 1, p. 435-559.

NOGUTI, I, 1967. Estudo das fácies carbonáticas da bacia de Barrerinhas, MA. Bol. Soc. Bras. de Geologia, S. Paulo, 16(1): 101-109.

PAMPLONA, N.P.R. 1969. Litoestratigrafia da bacia Cretácea de Barrerinhas. Bol.Téc. Petrobrás, 12(3):261-290.

PETRI, S. 1983. Brazilian cretaceous paleoclimates: evidence from clay minerals, sedimentary structures and palynomorphs. Rev. Bras. Geoc., 13(4):215-222.

PETTIJOHN, F.J.; POTTER, P.E.; SIEVER, R. 1973. Sands and sandstones. New York, Springer Verlag. 618 p.

PITTMAN, E.D. 1979. Porosity, diagenesis and prodủctive capability of sandstone reservoir. In: SCHOLLE, P.A. \& SCHLUGER, P. eds. Aspects of diagenesis. Tulsa, OK. Soc. of Economic Paleont. and Mineralogists. p. 159-173. (Special Publ. 26)

READING, H.G, 1980. Characteristics and recognition of strike-slip fault systems. In: BALLANCE, P.E. \& READING, H.G. eds Sedimentation in oblique-slip mobile zones. Oxford, Int. Assoc. Sedimentology 4:105-125. Spec. Publ.

RODRIGUES, R.; VASCONCELOS, D.N.; CASTRO, J.C. 1969. Estudo sedimentológico das formaçōes albianas e cenomanianas da bacia de Barreirinhas. Belém, Petrobrás Denor. 52 p. (Rel. Interno).

SCHMIDT, V. \& McDONALD, D.A. 1979a. The role of secondary porosity in the course of sandstone diagenesis. In: SCHOLLE P.A. \& SCHLUGER, P eds, Aspects of diagenesis. Tulsa. Soc. of Economic Paleont. and Mineralogists.p. 175-207.(Special Publ. 26)

SCHMIDT, V: \& McDONALD, D.A. 1979b. Textures and recognition of secondary porosity in sandstones, In: SCHOLLE, P.A. \& SCHLUGER, P.R. eds, Aspects of diagenesis. Tulsa, Soc. of Economic Paleont. and Mineralogists. p. 209-225.(Spec. Publ. 26)

SHANMUGAM, G. 1985. Significance of secondary porosity in interpreting sandstone composition. Am. Assoc. Petrol. Geol. Bull. 69(3):378-384

SURDAM, R.; BOESE, S.W.; CROSSEY, L.J. 1984. The chemistry of secondary porosity. In: McDONALD, D.A. \& SURDAM. R. eds. Clastic diagenesis. Tulsa, OK. Am. Assoc. of Petrol. Geol. p. 127-149. (Memoir 37)

TAYLOR, J.M. 1950. Pore space reduction in sandstones. Am. Assoc. Petrol. Geologists Bul., 34:701-716.

WALKER, R.G. 1967. Turbidite sedimenary structures and their relationships to proximal and distal depositional environments. Jour. Sed. Petrol., 37(1):25-43.

ZEMBRUSKY, S.G. \& AZEVEDO, R. P. de. 1987. Estudo geotérmico da bacia de Barrerinhas. Rio de Janeiro, Petrobrás/Cenpes. 159 p. (Rel. Interno)

ZUFFA, G.G, 1985. Optical analysis of arenites: influence of methodology on composition results. In: ZUFFA. G.G. ed. Provenance of arenites, Dordrecht. D. Reidel Publ. p. 165-190. (Series C 148).

MANUSCRITO 519

Recebido em 08 de janeiro de 1988 Aceita em 03 de junho de 1988

\section{NOTÍCIAS}

\section{PRINCIPAIS DEPÓSITOS MINERAIS DO BRASIL}

O DNPM lançou em março de 1988 o Volume II, sobre Ferro e Metais da Indústria do Aço da coleção "Principais Depósitos Minerais do Brasil". A obra, elaborada pelo Departamento Nacional da Produção Mineral e publicada pelo mesmo em convênio com a Companhia Vale do Rio Doce, acha-se à disposição dos interessados na Divisão de Geologia e Mineralogia daquele órgão.

Por outro lado, o Volume III - Metais Básicos Não-Ferrosos, Ouro e Alumínio deverá ser impresso ainda em 1988 enquanto que o Volume IV - Rochas e Minerais Industriais deverá ter sua compilação encerrada no $2^{\circ}$ semestre de 1988 , devendo ser impresso no início de 1989. 